\title{
Tradução e canonização na história da geografia
}

Dois momentos da recepção de Vidal de la Blache no Brasil (1982 e 2020)

Translation and canonization in the history of geography: two moments of the Paul Vidal de la Blache's Brazilian reception (1982 and 2020)

Traduction et canonisation dans l'histoire de la géographie : deux moments de la réception de Paul Vidal de la Blache au Brésil (1982 et 2020)

Traducción y canonización en la historia de la geografía: dos momentos de la recepción de Vidal de la Blache en Brasil (1982 y 2020)

\section{Guilherme Ribeiro}

\section{(2) OpenEdition}

Journals

Edição electrónica

URL: https://journals.openedition.org/terrabrasilis/7004

DOI: $10.4000 /$ terrabrasilis.7004

ISSN: 2316-7793

Editora

Rede Brasileira de História da Geografia e Geografia Histórica

Refêrencia eletrónica

Guilherme Ribeiro, «Tradução e canonização na história da geografia», Terra Brasilis [Online], 14 | 2020, posto online no dia 31 dezembro 2020, consultado o 05 dezembro 2022. URL: http://

journals.openedition.org/terrabrasilis/7004 ; DOI: https://doi.org/10.4000/terrabrasilis.7004

Este documento foi criado de forma automática no dia 5 dezembro 2022.

All rights reserved 


\section{Tradução e canonização na história da geografia}

Dois momentos da recepção de Vidal de la Blache no Brasil (1982 e 2020)

Translation and canonization in the history of geography: two moments of the

Paul Vidal de la Blache's Brazilian reception (1982 and 2020)

Traduction et canonisation dans l'histoire de la géographie : deux moments de la réception de Paul Vidal de la Blache au Brésil (1982 et 2020)

Traducción y canonización en la historia de la geografía: dos momentos de la recepción de Vidal de la Blache en Brasil (1982 y 2020)

\section{Guilherme Ribeiro}

\section{NOTA DO AUTOR}

Pelo pioneirismo e pela interlocução horizontal nos últimos dez anos, agradeço e dedico esse texto a Paul Claval (Université de Paris-Sorbonne). 0 presente trabalho integra o projeto Faperj "Centro de cálculo, redes de circulação e história da geografia: o caso da Revista Brasileira de Geografia do IBGE (1939-1996)" sob nossa direção.

\section{I}

1 Gentilmente convidado a apresentar a nova tradução brasileira de Des caractères distinctifs de la géographie, artigo publicado por Paul Vidal de la Blache em 1913 na revista fundada por ele e Marcel Dubois em 1891, os Annales de Géographie (Vidal de la Blache, 1913), a primeira inquietação a nos acometer foi a seguinte: por que retraduzir exatamente esse artigo? Para tentar esboçar uma resposta minimamente satisfatória, um caminho possível é o de recuperar a conjuntura político-intelectual envolvendo a primeira versão dessa tradução em português em 1982, bem como posicionar teoricamente o artigo no processo de elaboração da géographie humaine ao qual Vidal de 
la Blache dedicou boa parte de seus escritos entre o final do século XIX e seu falecimento em 1918.

II

2 Na falta de espaço suficiente para abordar questões aparentemente simples, porém repletas de complexidades, ao redor do campo da tradução, destaque-se apenas uma delas: o papel da agência (Tymoczko, 2000). Consagrada historicamente, a impressão segundo a qual o entendimento das ideias não precisaria estar associado a lugares de origem e de circulação afetou, inclusive, a tradução - muito embora sua compreensão passe, inexoravelmente, pela noção de deslocamento. Tal deslocamento, inútil dizer, foi elaborado e realizado por sujeitos em determinados lugares. Portanto, não estamos diante de algo natural, mas de uma escolha que não tem nada de aleatória; muito pelo contrário, ela é condicionada por elementos inscritos na ordem da geopolítica do conhecimento (Mignolo, 2003 [2000]), ordem esta que incide notadamente sobre países periféricos e obriga seus intelectuais à prática da diglossia, por exemplo (Casanova, 2015). Em síntese, a tradução é uma indução geográfica, ou seja, o leitor é levado a consumi-la naturalmente sem perceber que muitas dinâmicas e interesses - explícitas ou não, conscientes ou não - estão em jogo. Além disso, a natureza de sua recepção estará sujeita à "ordem discursiva" (cf. Foucault, 2004 [1971]) vigente, i.e., é mister examinar as circunstâncias histórico-intelectuais a fim de alcançar como determinada tradução será acolhida pelo campo em diferentes períodos (Rupke, 2000).

III

3 Em 1982, quando as eleições diretas para governadores estaduais e congressistas nacionais foram admitidas pela ditadura militar brasileira após quase vinte anos de interdição antidemocrática, publicava-se a coletânea Perspectivas da Geografia pela editora Difusão Européia do Livro (DIFEL). Seu organizador, o geomorfólogo Antonio Christofoletti, tanto trabalhava em um dos principais centros da geografia quantitativa no Brasil (a Unesp-Rio Claro) quanto era um de seus maiores representantes. Contudo, tal vertente vinha sendo fortemente questionada no mundo e no Brasil pelas abordagens tidas como radicais baseadas no materialismo histórico-dialético e, nesse movimento, os campos da história e da epistemologia ganhavam fôlego novo com livros-síntese dispostos a reescrever a geografia de baixo para cima - apropriando-se livremente da expressão de Harvey Kaye a respeito dos historiadores marxistas britânicos integrantes do The Group (Kaye, 1989 [1984]) —, tal como lemos em Introdução à geografia: geografia e ideologia, do historiador Nélson Werneck Sodré (Sodré, 1976); O que é Geografia, de Ruy Moreira (Moreira, 1980); e Geografia: pequena história crítica, de Antonio Carlos Robert Moraes (Moraes, 1981).

4 Chegado há pouco do exílio, no mesmo ano de 1982 Milton Santos já demonstrava a originalidade de sua reflexão tanto ao alertar para os perigos da marxificação da geografia, isto é, da imposição do materialismo à geografia sem considerar as mediações necessárias (Santos, 1982a), quanto ao propor a "construção de uma geografia brasileira descolonizada" (Santos, 1982b: 216) capaz de rejeitar a emulação de ideias importadas, atentar para as realidades nacionais na elaboração de uma teoria do 
espaço e promover um diálogo internacional não-hierárquico. 0 título da coletânea por ele organizada dava o tom da missão daqueles tempos tão férteis: Novos rumos da geografia brasileira (Santos, 1982c).

Obviamente, Christofoletti não estava alheio a isso. Entretanto, não deixa de ser curioso notar o fato de que ninguém percebeu sua coletânea (até onde nos foi permitido saber) como uma defesa de suas próprias convicções, seja no tocante à abordagem teoréticoquantitativa, seja diante das suspeitas em relação ao marxismo. Embora tenha incorporado duas importantes traduções de artigos de Richard Peet - um dos integrantes do movimento radical nos Estados Unidos associado à revista Antipode na segunda metade dos anos 1970 -, ao apresentar sua visão do livro como um todo no capítulo As perspectivas dos estudos geográficos Christofoletti encaminhou a seguinte avaliação:

$\mathrm{Na}$ perspectiva positivista as respostas e as soluções podem ser erradas e modificadas; procura-se melhorá-las e verificar sua validade pela refutação. Na perspectiva marxista as proposições não podem ser verificadas nem colocadas sob refutação. Elas são dogmáticas e as respostas e soluções são mais importantes que os problemas. Encontram-se já prontas as soluções marxistas para os problemas do mundo. (Christofoletti, 1982a: 28)

6 Seguindo os passos das traduções como objetos que nos auxiliam a reconstituir e a problematizar a história da geografia, de posse da informação segundo a qual a Revista Brasileira de Geografia verteu pela última vez um artigo "quantitativo" precisamente em 1982, tudo indica tratar-se dos últimos suspiros da spatial science no Brasil. No entanto, ela ainda mantinha algum fôlego para a batalha. Sob a aparência pedagógica de uma reunião de textos traduzidos nomeada inofensivamente Perspectivas da Geografia, o que estava em questão era uma disputa bourdieusiana-foucaultiana ao redor do poder e do discurso científicos. Nas entrelinhas, Christofoletti procurava uma possível sobrevida ou renovação do approach quantitativo representada pela "geografia econômica positiva" do estudioso da teoria dos lugares centrais Leslie J. King, pela time-space geography de Torsten Hägerstrand via Alan Pred e pela reprodução de um artigo sobre as características da nova geografia publicado pelo próprio Christofoletti originalmente na revista Geografia de Rio Claro em 1976. Além disso, seus esforços caminhavam no sentido de salvaguardar a geografia como o estudo das relações homem-meio mantendo amalgamados, portanto, seus ramos físico e humano - algo longe de ser consensual entre os geógrafos radicais de então -, tal como podemos extrair dos artigos de Albert Demangeon, Henri Baulig (geomorfólogo como Christofoletti, ressalte-se a título de indício) e Paul Vidal de la Blache.

\section{IV}

7 Se admitirmos as traduções como formas sutis de intervenção, quase quarenta anos depois - a última de Vidal de la Blache entre nós estivera a cargo do então iniciante Orlando Valverde junto ao Boletim Geográfico em 1944 e, assim como a de 1943, ambas caíram no esquecimento ${ }^{1}$ - Christofoletti trouxe ao Brasil um artigo cujo conteúdo tanto havia sido distorcido no passado quanto tinha tudo para sê-lo no momento em que, sufocados por quase vinte anos de modelos matemático-computacionais e de autoritarismo militar, parte dos geógrafos estava ávida por abordagens críticas capazes de explicar as contradições e as desigualdades de um espaço urbano-industrial periférico como o brasileiro. Se Christofoletti estava ciente da leitura de Yves Lacoste 
sobre Vidal de la Blache e a "escola vidaliana" em A geografia, isso serve, antes de mais nada, para fazer a guerra (Lacoste, 1988 [1976]) (a referência é encontrada no capítulo assinado por ele acima mencionado), muito provavelmente ele desconhecia a apropriação enviesada cometida pelo historiador francês Lucien Febvre a partir sobretudo de Des caractères distinctifs de la géographie. Após a morte de Vidal de la Blache em 1918, a proposta de uma "geografia humana modesta" tramada no início dos anos 1920 por Febvre à luz da inexistente dicotomia Ratzel determinista-Vidal de la Blache possibilista e da interdição da política e da economia aos domínios geográficos em prol da ênfase no meio físico transformou a frase vidaliana "La géographie est la science des lieux et non celle des hommes (...) [a geografia é a ciência dos lugares e não dos homens]" (Vidal de la Blache, 1913: 299) em um álibi a ser mobilizado por um projeto intelectual no qual a história dos Annales (caracterizada pela interdisciplinaridade e pela problematização e ampliação das fontes históricas a tudo o que disser respeito ao homem [do ambiente às fronteiras, inclusive]) assumiria o centro do campo e as demais ciências serviriam como auxiliares (Febvre, 1991 [1922]). O papel da geografia seria o de palco das ações humanas, tal como estampado pelo subtítulo de seu livro La terre et l'évolution humaine. Introduction géographique à l'histoire (Ribeiro, 2009).

8 Em nossas recordações de estudante de graduação no período compreendido entre 1998-2001, quase duas décadas depois da coletânea em tela As características próprias da geografia continuava a ser tomado como arquétipo da geografia "tradicional", isto é, das monografias limitadas ao descritivismo, à escala regional e aos empiricistas trabalhos de campo - tudo isso revestido sob a cobertura do positivismo de modo a não deixar nenhuma dúvida sobre sua "relevância" para a ciência e para o presente... Tal "interpretação" vinha inevitavelmente acompanhada da pergunta "para que servia essa geografia" e a resposta era tão uníssona quanto axiomática: "para mascarar a luta de classes"... Se a luta de classes indubitavelmente não era tema das geografias imperiais de Ratzel, Vidal de la Blache e Mackinder e se à luz do pensamento progressista as supressões científicas precisam ser levadas tão a sério quanto as admissões, o problema que estamos levantando reside no maniqueísmo e na superficialidade de raciocínios dessa espécie. Infelizmente, bem o sabemos: quanto mais raso, mais difundido...

9 A aceitação das teses de Febvre e de Lacoste não significa apenas a força da palavra da autoridade e da tradição; revela também um pensamento que, abrindo mão de caminhar por si próprio, torna-se colonizado - sem perceber.

\section{V}

No que concerne a uma tradução cujo intervalo de tempo em relação ao original salta aos olhos (mais de um século), a margem para que leituras distorcidas e descontextualizadas ocorram aumenta na mesma proporção da distância temporal. No que tange à recepção dos "clássicos" estrangeiros no Brasil, então, a tendência tem sido a de visualizar o todo pela parte; a dificuldade e a morosidade inerentes à montagem de um quebra-cabeças cujo resultado será o prazer proporcionado pela visão do conjunto têm sido substituídas sem nenhum pesar por uma, duas ou três peças "milagrosamente" traduzidas (sim, pois é como se do céu caíssem) para a língua portuguesa. E, uma vez que vieram do céu, como em um passe de mágica o campo fica aliviado e se satisfaz com o que lhe foi "concedido" crendo, fielmente, no que a tradução lhe atesta. Eis, por vezes, nossa impressão sobre como a história da geografia 
no Brasil é representada por aqueles que não se dedicam exclusivamente a ela: peças soltas, dispersas, cuidadosamente esquecidas em uma caixa rasa de "erudição". Pouco útil se não tiver aplicação prática contemporânea, eis o lugar da história da geografia: de costas para o presente.

Enfim, quais terão sido as motivações do tradutor em recuperar, trinta e oito anos depois de sua primeira versão nacional e dentre o rol de artigos legados por Vidal de la Blache, precisamente Des caractères distinctifs de la géographie? Subscrevendo a interpretação de Marc Bloch segundo a qual a história é mobilizada graças às inquietações dos homens do presente (Bloch, 2001 [1949]), em que medida o século XXI estimulou determinado colega a atuar como - na falta de expressão melhor geotradutor? Algo terá lhe chamado atenção em particular ou, em realidade, a argumentação como um todo? Terá ele discordado do que vem sendo publicado sobre Vidal de la Blache e, assim, a tradução aparece como o subtexto de uma mensagem dissonante? Especulações à parte (desprezá-las seria naturalizar a tradução, reitere-se), cremos ser oportuno aproveitar a ocasião para problematizar, ainda que brevemente, uma faceta da reflexão vidaliana.

$12 \mathrm{Na}$ inexistência dos ramos História Humana, Filosofia Humana, Sociologia Humana ou Antropologia Humana, o surgimento e a consagração da Geografia Humana expressam um movimento científico incomum visando correlacionar os elementos físico-naturais da superfície terrestre e o homem. Tal intento responde a uma conjuntura intelectual marcada pelo imperativo de delimitar objetos e métodos específicos a cada disciplina, como vinha ocorrendo com a Sociologia Durkheimiana e a História Metódica na França em finais do Novecentos (Durkheim, 2001 [1895]; (Langlois \& Seignobos, 1992 [1898]). Nesse sentido, Vidal de la Blache assim se manifesta em Des caractères:

No grupo das ciências naturais ao qual sem nenhuma dúvida a geografia está vinculada, ela detém um lugar à parte. As afinidades entre a geografia e as ciências naturais não excluem sensíveis diferenças. Assim, é sobretudo a respeito destas diferenças que falta precisão (...) A geografia se serve das mesmas fontes de fatos que a geologia, a física, as ciências naturais e, em certos aspectos, as ciências sociológicas. (Vidal de la Blache, 1913: 289, grifo nosso)

Continuando a oferecer serviços recíprocos, é útil, porém, que [geografia e história] tenham nítida consciência das divergências existentes entre seus pontos de partida $\mathrm{e}$ seus métodos. A geografia é a ciência dos lugares e não dos homens. Ela se interessa pelos acontecimentos da história na medida em que eles acionam e esclarecem, nos espaços onde ocorreram, propriedades, potencialidades as quais, sem eles, permaneceriam latentes. (idem, p.298-299, grifo nosso)

13 Tal argumentação é moldada pela ambiguidade, feição derivada tanto da complexidade da inovação sui generis criada por Ratzel (Ratzel, 1914 [1882]) e reelaborada por Jean Brunhes em seu livro La Géographie Humaine em 1910 (Brunhes, 1962 [1910]) e por Vidal de la Blache em diversos artigos (Vidal de la Blache, 2002 [1898], 1902, 1903, 1912, 1914) quanto da torção epistemológica a ser paga por sustentar a base darwinista (ou, no caso de Vidal de La Blache, neolamarckista (Berdoulay \& Soubeyran, 1991; Soubeyran, 1997) no exame de um objeto que não era nem totalmente biológico, nem totalmente social. 0 efeito dessa configuração foi o de ter costurado uma armadilha para si própria cuja expressão mais eloquente reside na inevitabilidade (e, com toda razão, na má-fama) de raciocínios deterministas. ${ }^{2}$ Além disso, o desenvolvimento capitalista relativizou como nunca os constrangimentos do meio e mostrou que a adaptação humana, dispondo do incremento da técnica, acelerava a escala geológica responsável pela evolução das plantas e dos animais. Era a antessala do Antropoceno e, ao mesmo tempo, do declínio 
de uma geografia cuja "missão especial [era] pesquisar como as leis físicas ou biológicas que regem o globo se combinam e se modificam ao serem aplicadas às diversas porções da superfície" (Vidal de la Blache, 1913: 291-292). Essa referida ambiguidade carece ainda de um terceiro elemento a ser considerado: vivendo entre 1845 a 1918, Vidal de la Blache testemunhou mudanças estruturais na paisagem e na organização espacial promovidas pela industrialização e pela urbanização, mas tais mudanças estavam apenas em seu início - sobretudo em um país caracterizado pelo peso rural como a França. Assim, ajuda a dissipar a ambiguidade em tela ler a obra vidaliana como obra de transição na qual, se de um lado parte representativa é dedicada à geografia sob uma perspectiva geológica de tempo em que por conseguinte o homem assume papel coadjuvante face às dimensões da natureza, ${ }^{3}$ por outro ângulo ao acentuar os componentes políticos, econômicos e urbanos no coração da dinâmica imperialista vários trabalhos parecem escapar ao edifício teórico que o próprio Vidal arquitetou, deixando para trás uma concepção de ciência social típica do século XIX e projetando seu legado rumo à geografia humana praticada em nossos dias (vide, p.ex., Vidal de la Blache, 1908, 1910, 1910a, 1911, 1912a, 1917, 1917a). ${ }^{4}$

14 Atordoado pela celeridade histórica, sob o prisma geográfico o predomínio das escalas local e regional cede lugar a um mundo permeado pela circulação nos grandes espaços nacionais e internacionais e no qual a economia capitalista vai incorporar (sem, contudo, suprimir) atividades de subsistência, empórios e feiras locais. As regiões deixariam de ser concebidas como "naturais" e passariam a ser polarizadas; as cidades não eram mais apenas cités e villes contrastantes com o campo, mas cidades regionais ampliando sobremaneira o alcance de sua influência. Por isso Principes de Géographie Humaine (1954 [1921]) (síntese de sua trajetória e ambição intelectuais) pode ser tomado como uma geografia histórica de longa duração: seu intuito é o de retraçar um processo multissecular de emancipação humana em relação ao meio desde os artefatos primitivos, passando pelos gêneros de vida agrícolas até chegar às grandes cidades do início do século, com destaque para a "Babel insaciável" simbolizada por Nova Iorque (Ribeiro 2014).

15 Se nossa explanação admitir um mínimo de plausibilidade, ela nos impele a concluir que alguns textos e interpretações foram canonizados em detrimento de outros (Ribeiro, Haesbaert \& Pereira 2012), fenômeno que pode ser estendido à história da geografia praticada em outros lugares e tradições ( $c f$. Keighren, Abrahamsson \& della Dora, 2012).

\section{VI}

À guisa de conclusão, tais notas não passam de sugestões, de um convite (sedutor ou enfadonho) à leitura de Des caracteres distinctifs de la géographie, traduzido pela segunda vez em português desde sua primeira versão em 1982 na coletânea Perspectivas da Geografia a cargo do geomorfólogo Antonio Christofoletti. Se Paul Vidal de la Blache ainda continua a ser traduzido em pleno ano de 2020 não mais como um geógrafo "tradicional", mas como um intérprete da modernidade, eis um belo testemunho de sua vitalidade - traço à altura daqueles que reconhecemos como clássicos. Independente dos objetivos do tradutor e do apresentador, grife-se, antes de tudo, a necessidade de reconhecer a tradução como objeto científico intencional - e não algo casual ou natural, nem tampouco inócua emulação - capaz de fazer girar a roda transnacional da história da geografia. 


\section{BIBLIOGRAFIA}

Berdoulay, Vincent, Soubeyran, Olivier (1991). "Lamarck, Darwin et Vidal: aux fondements naturalistes de la géographie". Annales de Géographie, t.100, n. 561-562, numéro du centenaire, pp. 617-634.

Bloch, Marc (2001 [1949]). Apologia da História ou O Ofício de Historiador. Rio de Janeiro: Jorge Zahar Editor. 160p.

Brunhes, Jean (1962 [1910]). Geografia Humana. Rio de Janeiro: Editora Fundo de Cultura. Trad. de Ruth Magnanini. 507 p.

Casanova, Pascale (2015) La langue mondiale. Traduction et domination. Paris : Seuil. 129p.

Christofoletti, Antonio (org.). (1982). Perspectivas da Geografia. São Paulo: Difel. 318p.

Christofoletti, Antonio (1982a). “As perspectivas dos estudos geográficos”. In: Christofoletti, Antonio (org.). Perspectivas da Geografia. São Paulo: Difel, pp. 11-36.

Durkheim, Émile (2001 [1895]). As Regras do Método Sociológico. São Paulo: Martin Claret. Tradução de Bruno Charles Magne. $158 \mathrm{p}$.

Febvre, Lucien (1991 [1922]). A Terra e a Evolução Humana. Introdução Geográfica à História. $2^{\mathrm{a}}$ ed. Lisboa: Cosmos. Tradução de Jorge Borges de Macedo. 339p.

Foucault, Michel (2004 [1971]). A ordem do discurso. São Paulo: Loyola. Tradução de Laura Fraga de Almeida Sampaio. 80p.

Kaye, Harvey J. (1989 [1984]). Los Historiadores Marxistas Britanicos. Zaragoza: Prensas Universitarias. Versión castellana: Pilar Navarro Errasti. 240p.

Keighren, Innes M.; Abrahamsson, Christian; della Dora, Veronica (2012). “On canonical geographies". Dialogues in Human Geography, v. 2, n. 3, pp. 296-312.

Lacoste, Yves (1988 [1976]). A Geografia - isso serve, em primeiro lugar, para fazer a guerra. Campinas: Papirus. Tradução de Maria Cecília França. 240p.

Langlois, Charles-Victor, Seignobos, Charles (1992 [1898]). Introduction aux Études Historiques. Paris: Kimé. 284p.

Mignolo, Walter D. (2003 [2000]) Histórias locais/projetos globais: colonialidade, pensamento liminar e saberes subalternos. Belo Horizonte: Editora da UFMG. Tradução de Solange Ribeiro de Oliveira. $505 \mathrm{p}$.

Moraes, Antônio Carlos Robert (1981). Geografia: pequena história crítica. São Paulo: Hucitec. 152p. Moreira, Ruy (1980). o que é Geografia. São Paulo: Brasiliense. 90p.

Ratzel, Friedrich (1914 [1882]). Geografia dell'uomo (Antropogeografia): principi d'applicazione della scienza geografica alla storia. Milano-Torino-Roma: Fratelli Bocca Editori. Tradução de Ugo Cavallero. 596 p.

Ribeiro, Guilherme (2014). "Question régionale, identité nationale et émergence du monde urbain-industriel. La modernité dans l'œuvre de Paul Vidal de la Blache". Annales de Géographie (Paris), v. 699, pp. 1215-1238.

Ribeiro, Guilherme, Haesbaert, Rogério, Pereira, Sergio Nunes (2012). "Relendo Vidal: em busca de novos enfoques”. In: Haesbaert, Rogério, Pereira, Sergio Nunes, Ribeiro, Guilherme (orgs.). 
Vidal, Vidais: textos de Geografia Humana, Regional e Política. Rio de Janeiro: Bertrand Brasil, pp. 13-19.

Ribeiro, Guilherme (2009). "Para ler geografia ou A geografia segundo Lucien Febvre”. Terra Livre (AGB), n. 32, p. 121-145.

Rupke, Nicolaas (2000). "Translation studies in the history of science: the example of Vestiges". British Journal for the History of Science, v. 33, n. 2, pp. 209-222.

Santos, Milton (2002 [1996]). A Natureza do Espaço. Técnica e Tempo. Razão e Emoção. São Paulo: Edusp. 308p.

Santos, Milton (1982a). “Alguns problemas atuais da contribuição marxista à geografia”. In: Santos, Milton (org.) Novos Rumos da Geografia Brasileira. São Paulo: Hucitec, pp. 131-133.

Santos, Milton (1982b). "Novos rumos para a geografia brasileira”. In: Santos, Milton (org.). Novos rumos da geografia brasileira. São Paulo: Hucitec (1982), pp. 209-219.

Santos, Milton (org.) (1982c). Novos rumos da geografia brasileira. São Paulo: Hucitec. 219p.

Sodré, Nélson Werneck. Introdução à Geografia. Petrópolis: Vozes (1976). 135p.

Soubeyran, Olivier. Imaginaire, science et discipline. Paris: L'Harmattan (1997). 482p.

Tymoczo, Maria (2000). "Translation and political engagement. Activism, social change and the role of translation in geopolitical shifts". The Translator, v. 6, n. 1, pp. 23-47.

Vidal de la Blache, Paul (1954 [1922]). Princípios de Geografia Humana. Lisboa: Cosmos. 390p. Tradução e prefácio de Alfredo Fernandes Martins.

Vidal de la Blache, Paul (1917). "La rénovation de la vie régionale ». Foi et Vie, Les questions du temps présent, Cahier B, n. 9, mai, p. 103-110.

Vidal de la Blache, Paul (1917a). La France de l'Est (Lorraine-Alsace). Paris: La Découverte. 285p.

Vidal de la Blache, Paul (1914). "Sur l'esprit géographique". Revue politique et littéraire (Revue Bleu), n. 13, 1er sem., 52e année, 2 mai. Paris: Bureaux de la Revue Politique et littéraire (Revue Bleu) et de la Revue Scientifique, pp. 556-560.

Vidal de la Blache, Paul (1913). "Des caractères distinctifs de la géographie". Annales de Géographie, année XXII, n.124, pp. 289-299.

Vidal de la Blache, Paul (1912). "Sur le sens et l'objet de la géographie humaine". Revue politique et littéraire, n.17, année L, avril pp. 513-515 et pp. 548-551.

Vidal de la Blache, Paul (1912a). "Les chemins de fer en Amérique". France-Amérique, février, pp. 69-78.

Vidal de la Blache, Paul (1944 [1912]). "Sentido e objeto da geografia humana". Boletim Geográfico, v. 2, n. 13, pp. 18-25. Tradução de Orlando Valverde.

Vidal de la Blache, Paul (1911). "La relativité des divisions régionales". Athéna, Conférence à l'École des Hautes Études Sociales, pp. 1-14.

Vidal de la Blache, Paul (1910a). "Régions Françaises". La Revue de Paris, déc., pp. 821-849.

Vidal de la Blache, Paul (1910). "La carte internationale du monde au milionième". Annales de Géographie, année XIX, n. 103, pp. 1-7.

Vidal de la Blache, Paul (1908). "La Colombie Britannique, par A. Métin". Annales de Géographie, année XVII, n. 94, pp. 364-366. 
Vidal de la Blache, Paul (1943 [1907]). "O ensino de geografia na escola primária". Boletim do Conselho Nacional de Geografia, v. 1, n. 1, pp. 18-24. Sem indicação de tradutor.

Vidal de la Blache, Paul (1903). "La géographie humaine. Ses rapports avec la géographie de la vie". Revue de Synthèse Historique, 7, août-décembre, pp. 219-240.

Vidal de la Blache, Paul (1902). "Les conditions géographiques des faits sociaux". Annales de Géographie, année XI, n. 55, pp. 13-23.

Vidal de la Blache Paul (2002 [1898]). "A Geografia Política. A propósito dos escritos de Friedrich Ratzel". GEOgraphia (UFF), n. 7, ano 4, pp. 122-137. Tradução de Rogério Haesbaert e Sylvain Souchaud.

\section{NOTAS}

1. Referimo-nos a 0 ensino de geografia na escola primária e Sentido e objeto da geografia humana (Vidal de la Blache, 1944 [1907], 1943 [1912]).

2. "Quantas frases têm sido repetidas sobre o ar de atonia e de tristeza que exprime a fisionomia desses indígenas da América! o facto é real. Eu recordo-me de ter ficado surpreendido, no México, com a falta de movimento e de alegria, até dos próprios garotos, naqueles grupos que se formavam para as refeições às voltas do cais das estações. Não seria isto apenas um simples efeito da hereditariedade fisiológica?" (Vidal de la Blache, 1954: 163 [1921]).

3. Tal raciocínio, aliás, é o que justifica a distinção entre geografia e história, entre a ciência dos lugares e a ciência dos homens. No ano seguinte, Vidal redige Sur l'esprit géographique dando a entender que precisava esclarecer o raciocínio apresentado em Des caractères - não por acaso a única referência do próprio Vidal citada no texto. Sendo o tempo uma "coordenada histórica", o lugar seria uma "coordenada geográfica". Assim, para serem compreendidos em sua totalidade os fenômenos modernos não poderiam prescindir dos lugares onde ocorriam e dos efeitos por eles provocados (Vidal de la Blache, 1914: 558).

4. Um exemplo útil seria comparar os Principes de Géographie Humaine (1954 [1921]) com A natureza do espaço (Santos, 1996).

\section{RESUMOS}

O surgimento de uma nova versão em português do artigo Des caractères distinctifs de la géographie (1913), de Paul Vidal de la Blache, abre a possibilidade de refletirmos sobre os caminhos da história da geografia praticada no Brasil. Para tanto, recuperamos o contexto referente à primeira tradução em português na coletânea organizada pelo geomorfólogo Antonio Christofoletti Perspectivas da Geografia (1982), bem como situamos o artigo original no interior da geografia humana concebida por Vidal de la Blache entre o final do século dezenove e início do vinte. A conclusão é a de que a conjuntura histórico-intelectual é essencial para entender as diferentes recepções do pensamento vidaliano no Brasil, bem como sublinha o papel central da tradução na história transnacional da geografia vista sob a ótica de um país periférico. 
The arrival of a new version in Portuguese from Paul Vidal de la Blache's Des caractères distinctifs de la géographie (1913) opens up some issues related to the practice of history of geography in Brazil. To do so, I retrace the intellectual context concerning the first translation into Portuguese from that text in 1982 published by geomorphologist Antonio Christofoletti's Perspectivas da Geografia (1982), as well as situate the original version into human geography' intellectual project conceived by Vidal de la Blache between the end of the XIXth century and the first of the XXth century. I conclude that intellectual conjuncture is crucial to understand the different reception of the Vidalian thinking in Brazil, besides highlight the central role of translation for the transnational history of geography from a peripheral point of vue.

L'apparution d'une nouvelle version en Portugais de l'article Des caractères distinctifs de la géographie (1913) nous amène à réfléchir sur l'histoire de la géographie pratiquée au Brésil. Pour cela, j'ai repris la conjoncture intellectuelle liée à la première traduction de cet article, publiée dans le recueil de textes Perspectivas da Geografia (1982) organisée par Antonio Christofoletti. En outre, j'ai mis la version originale à l'intérieur du projet d'élaboration de la géographie humaine conçue par Vidal de la Blache entre la fin du XIXème siècle et le début du XXème. La conclusion montre comment le contexte intellectuel est vital pour comprendre les différentes réceptions de la pensée vidalianne au Brésil, ainsi que le rôle centrale de la traduction en ce qui concerne à une histoire transnational de la géographie vue à partir d'un pays périphérique.

La aparición de una nueva versión portuguesa del artículo Des caractères distinctifs de la géographie (1913), de Paul Vidal de la Blache, abre la posibilidad de reflexionar sobre los caminos de la historia de la geografía practicada en Brasil. Para ello, recuperamos el contexto referente a la primera traducción al portugués de la colección organizada por el geomorfólogo Antonio Christofoletti Perspectivas da Geografia (1982), además de situar el artículo original dentro de la geografía humana concebida por Vidal de la Blache entre los finales del siglo XIX y principios de los años veinte. La conclusión es que la coyuntura histórico-intelectual es fundamental para comprender las diferentes recepciones del pensamiento vidaliano en Brasil, así como subraya el papel central de la traducción en la historia transnacional de la geografía vista desde la perspectiva de un país periférico.

\section{ÍNDICE}

Índice geográfico: Brasil, França

Palavras-chave: tradução, recepção, canonização, história da geografia brasileira, Paul Vidal de la Blache

Palabras claves: traducción, recepción, canonización, historia de la geografía brasileña, Paul Vidal de la Blache

Índice cronológico: 1913, 1982, 2020

Keywords: translation, reception, canonization, history of Brazilian geography, Paul Vidal de la Blache

Mots-clés: traduction, réception, canonisation, histoire de la géographie brésilienne, Paul Vidal de la Blache 


\section{AUTOR}

\section{GUILHERME RIBEIRO}

Universidade Federal Rural do Rio de Janeiro, Departamento de Geografia, Programa de PósGraduação em Geografia, Laboratório Política, Epistemologia e História da Geografia(UFRRJ/DGG/ PPGGEO/LAPEHGE).

Email: lapehge@gmail.com 